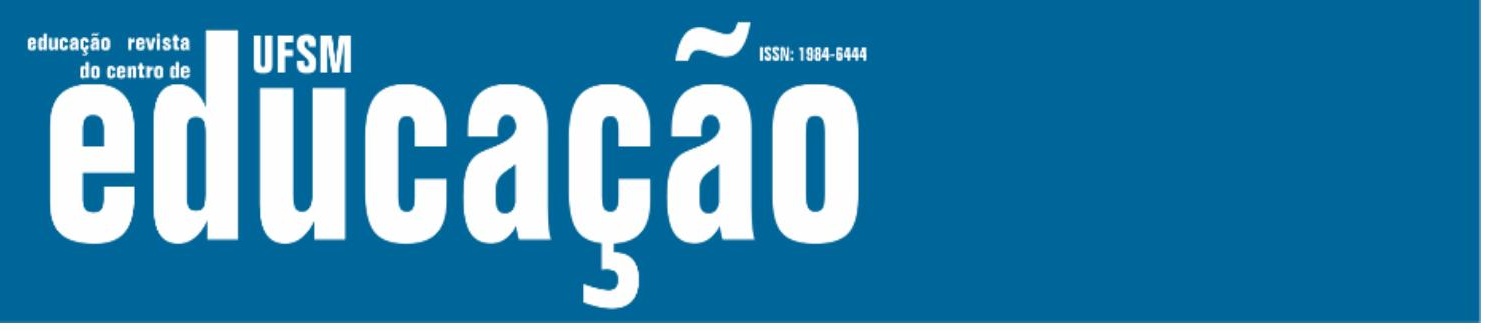

ISSN: 1984-6444 | http://dx.doi.org/10.5902/1984644442654

\title{
Fatores Potencializadores e/ou Dificultadores do Processo de Inclusão de alunos com deficiência nas aulas de Educação Física
}

\section{Potential and/or Difficulty Factors of the Inclusion Process of students with disabilities in Physical Education class}

Francianne Farias dos Santos

Doutoranda na Universidade Federal do Amazonas, Manaus, Amazonas, Brasil. franci.anne.farias@hotmail.com - http://lattes.cnpq.br/7628860808088698

Maria Almerinda de Souza Matos

Professora doutora na Universidade Federal do Amazonas, Manaus, Amazonas, Brasil. profalmerinda@hotmail.com - https://orcid.org/0000-0001-6417-9001

João Otacilio Libardoni dos Santos

Professor doutor na Universidade Federal do Amazonas, Manaus, Amazonas, Brasil. jlibardoni@ufam.edu.br - https://orcid.org/0000-0002-1048-8164

Recebido em 28 de fevereiro de 2020

Aprovado em 13 de junho de 2020

Publicado em 21 de dezembro de 2020

\section{RESUMO}

A educação escolar pública é um direito garantido e conquistado para todos, em que ninguém poderá ser excluído do ambiente educacional. Assim ao refletirmos sobre as diversas disciplinas que compõem a escola, destacamos a Educação Física como parte integrante deste espaço. Diversos pontos podem surgir como fatores que potencializam ou dificultam a inclusão de alunos com deficiência nas aulas de Educação Física. Entende-se que o conhecimento prévio destes fatores poderá auxiliar os professores a romperem diversas barreiras. Sendo assim, o presente trabalho teve como objetivo discutir elementos que se apresentam como potencializadores e/ou dificultadores na inclusão de alunos com deficiência nas aulas de Educação Física, a partir de estudos que investigaram estratégias de inclusão. A pesquisa foi realizada no Portal de Periódicos CAPES e SciELO, em que utilizamos os descritores ((educação física) AND inclusão) OR ((educação física) AND deficiência). Após a aplicação de nossos critérios de inclusão e exclusão, mantiveramse 22 artigos para a exploração. Com base nos estudos encontrados, foi possível identificar três pontos que podem potencializar ou dificultar a inclusão nas aulas Educação Física: Estratégias de Ensino, Trabalho Colaborativo e Formação.

Palavras-chave: Inclusão Escolar; Educação Física; Aluno com Deficiência. 


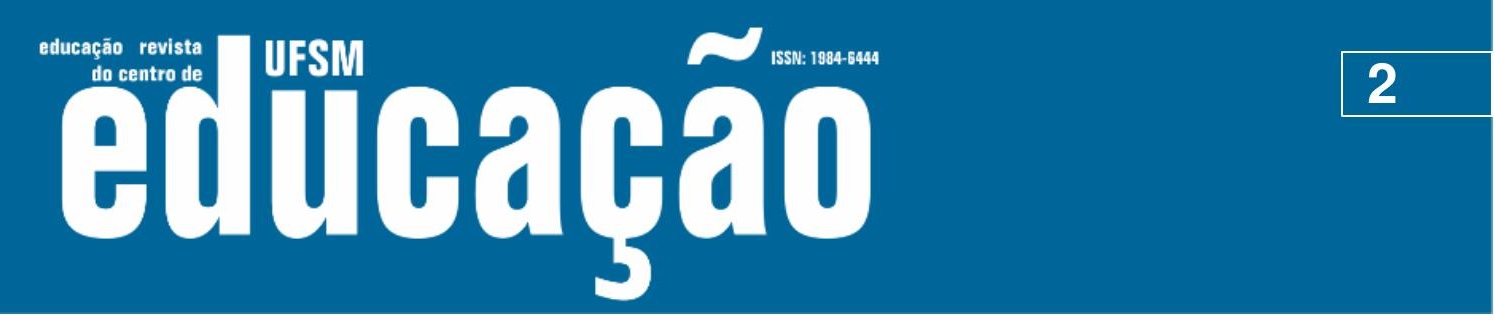

ISSN: 1984-6444 | http://dx.doi.org/10.5902/1984644442654

\section{ABSTRACT}

Public education is a right guaranteed to all and conquered, where no one can be excluded from the educational environment. So when we reflect on the various disciplines that make up the school, we highlight the Physical Education as part of this space. Several points can emerge as factors that enhance or hinder the inclusion of students with disabilities in physical education classes. It is understood that prior knowledge of these factors may help teachers to break several barriers. Therefore, this study aimed to discuss elements posing as enhancers and / or hindering the inclusion of students with disabilities in physical education classes, from studies investigating inclusion strategies. The survey was conducted from the search work in CAPES Journal Portal and SciELO, in which we use the descriptors ((physical education) AND inclusion) OR ((physical education) AND disabilities). After application of our criteria for inclusion and exclusion, remained 22 articles for exploration. Based on these studies, it was possible to identify three points that can enhance or hinder the inclusion in class Physical Education: Teaching Strategies, Collaborative Work and Training.

Keywords: School inclusion; Physical Education; Student with Disability.

\section{Introdução}

A Declaração Universal dos Direitos da Criança com base na Declaração Universal dos Direitos Humanos de 1959 promulgou o direito de toda criança à Educação, sem discriminação, independente do seu credo, cor, raça, sexo ou qualquer outra situação e apresenta em seu Princípio $5^{\circ}$ os benefícios igualitários da criança deficiente. Outro ponto importante deste documento é abordado em seu Princípio $7^{\circ}$, onde indica que toda criança deverá ter a oportunidade de participar de atividades recreativas e brincar, constando nessas ações, entre outros objetivos: o de educar.

Neste mesmo caminho, a Constituição Federal Brasileira de 1988 e a Convenção de Guatemala de 1999 se destacam como marcos da luta por uma escola plural, justa e democrática que garanta o direito a educação escolar pública, independente das especificidades de cada ser humano. Ainda, a Declaração de Salamanca de 1994 salienta que as escolas regulares devem buscar meios de educar a todos sem distinção, de forma bem-sucedida, utilizando estratégias de ensino, currículo e recursos apropriados, arranjos organizacionais e parcerias com as 


\section{$\sim 7$

ISSN: 1984-6444 | http://dx.doi.org/10.5902/1984644442654

uma das palavras do string de busca em seu texto, entretanto, estavam relacionadas à pesquisas que fugiam do nosso objetivo de investigação; as bibliográficas; as que retratavam esporte adaptado e inclusão; um (1) artigo com data de publicação anterior a 2008, selecionando, a partir disso, 60 trabalhos para a análise da elegibilidade (Fluxograma 1).

Após a leitura integral dos 60 artigos, excluímos os que atingiram ao menos um dos critérios da segunda extração. A observação de algumas características dos trabalhos só foi possível a partir da leitura completa, em que ainda encontramos trabalhos não relacionados ao nosso tema; bibliográficos ou com o tema esporte adaptado e inclusão. Mantiveram-se, dessa maneira, 22 artigos ao final (Quadro 1). No quadro 1, é possível observar itens que sintetizam as principais informações dos trabalhos selecionados e que nos auxiliaram a responder o objetivo da pesquisa. 


\section{usm

ISSN: 1984-6444 | http://dx.doi.org/10.5902/1984644442654

\section{Fluxograma 1 - Processo de Seleção dos trabalhos}
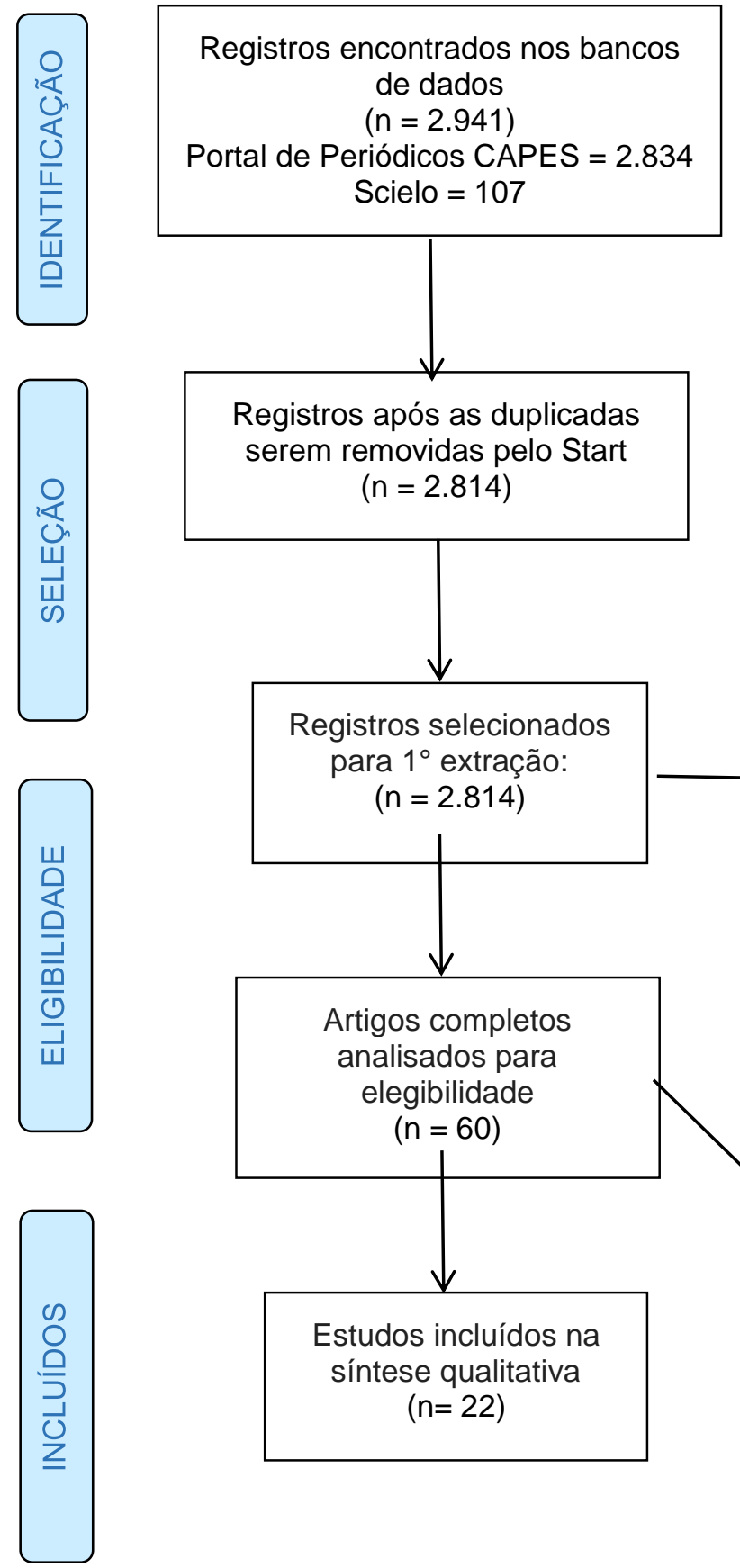

Registros após as duplicadas
serem removidas pelo Start $(n=2.814)$
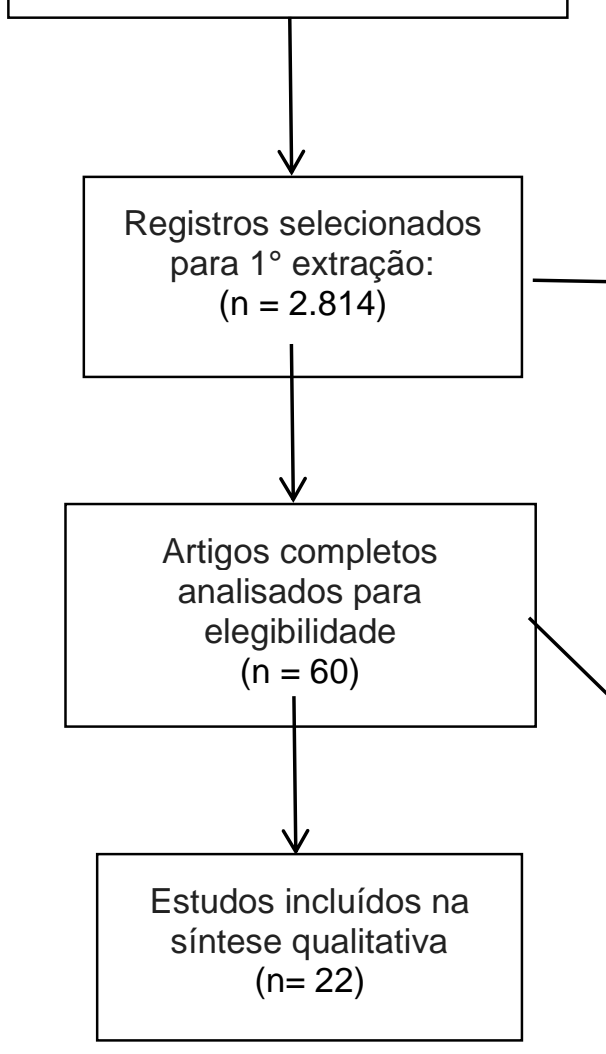

Registros excluídos após a 1를 extração $(\mathrm{n}=$ 2.754)

Registros excluídos por não apresentarem os strings de busca no título, resumo e palavras-chave $(n=2.195)$

Trabalho inferior ao ano de $2008(n=1)$

Não relacionado ao Tema da pesquisa $(n=$ 542)

Trabalhos Bibliográficos $(n=10)$

Esporte Adaptado e Inclusão $(n=6)$ 


\section{usm

ISSN: 1984-6444 | http://dx.doi.org/10.5902/1984644442654

Quadro 1 - Trabalhos Selecionados

\begin{tabular}{|c|c|c|c|c|c|c|}
\hline TÍTULO & OBJETIVO & $\begin{array}{l}\text { CONCLUSÃO } \\
\text { PRINCIPAL }\end{array}$ & ANO & AUTORES & INSTRUMENTO & PARTICIPANTES \\
\hline $\begin{array}{c}\text { Estratégias } \\
\text { de } \\
\text { professores } \\
\text { de Educação } \\
\text { Física para } \\
\text { promover a } \\
\text { participação } \\
\text { de alunos } \\
\text { com } \\
\text { deficiência } \\
\text { auditiva nas } \\
\text { aulas }\end{array}$ & $\begin{array}{c}\text { Analisar as } \\
\text { estratégias de } \\
\text { sucesso } \\
\text { utilizadas por } \\
\text { professores de } \\
\text { EF para } \\
\text { promover a } \\
\text { participação } \\
\text { de alunos com } \\
\text { deficiência } \\
\text { auditiva nas } \\
\text { mesmas } \\
\text { atividades que } \\
\text { os demais } \\
\text { alunos da } \\
\text { turma }\end{array}$ & $\begin{array}{c}\text { Concluiu-se que } \\
\text { para criar condições } \\
\text { favoráveis, a } \\
\text { participação de } \\
\text { alunos com } \\
\text { deficiência auditiva } \\
\text { em aulas de EF, } \\
\text { foram necessárias } \\
\text { estratégias } \\
\text { direcionadas a } \\
\text { diferentes aspectos } \\
\text { de uma mesma } \\
\text { aula. }\end{array}$ & 2018 & $\begin{array}{c}\text { Maria Luiza } \\
\text { Salzani } \\
\text { Fiorini; } \\
\text { Eduardo } \\
\text { José } \\
\text { Manzini }\end{array}$ & $\begin{array}{c}\text { Filmagem das } \\
\text { aulas }\end{array}$ & $\begin{array}{c}3 \text { Professores de } \\
\text { EF e } 3 \text { alunos com } \\
\text { deficiência } \\
\text { auditiva }\end{array}$ \\
\hline $\begin{array}{l}\text { Inclusão de } \\
\text { alunos com } \\
\text { deficiência } \\
\text { nas aulas de } \\
\text { Educação } \\
\text { Física: } \\
\text { atitudes de } \\
\text { professores } \\
\text { nas escolas } \\
\text { regulares }\end{array}$ & $\begin{array}{c}\text { Analisar as } \\
\text { atitudes dos } \\
\text { professores de } \\
\text { EF em relação } \\
\text { à inclusão de } \\
\text { alunos com } \\
\text { deficiência no } \\
\text { ensino regular, } \\
\text { bem como a } \\
\text { influência do } \\
\text { sexo, tempo } \\
\text { de experiência } \\
\text { profissional e } \\
\text { tipo de } \\
\text { deficiência dos } \\
\text { alunos }\end{array}$ & $\begin{array}{l}\text { Os resultados } \\
\text { mostraram que, de } \\
\text { um modo geral, os } \\
\text { professores são } \\
\text { otimistas com } \\
\text { relação à inclusão } \\
\text { de alunos com } \\
\text { deficiência em suas } \\
\text { aulas, embora seja } \\
\text { destacada a falta de } \\
\text { apoio recebido pela } \\
\text { escola como uma } \\
\text { barreira importante } \\
\text { no processo. }\end{array}$ & 2018 & $\begin{array}{c}\text { Marcia } \\
\text { Greguol; } \\
\text { Bruno } \\
\text { Marson } \\
\text { Malagodi; } \\
\text { Attilio } \\
\text { Carraro }\end{array}$ & $\begin{array}{c}\text { Teacher } \\
\text { Inclusion } \\
\text { Attitudes } \\
\text { Questionnaire } \\
\text { (TIAQ) }\end{array}$ & $\begin{array}{c}35 \text { professores de } \\
\text { EF }\end{array}$ \\
\hline $\begin{array}{c}\text { Adaptações } \\
\text { curriculares } \\
\text { nas aulas de } \\
\text { Educação } \\
\text { Física } \\
\text { envolvendo } \\
\text { estudantes } \\
\text { com } \\
\text { deficiência } \\
\text { visual }\end{array}$ & $\begin{array}{c}\text { Analisar e } \\
\text { descrever as } \\
\text { adaptações } \\
\text { nos elementos } \\
\text { base do } \\
\text { currículo } \\
\text { comum, } \\
\text { empregadas } \\
\text { por } \\
\text { professores de } \\
\text { EF, voltadas à } \\
\text { participação } \\
\text { de estudantes } \\
\text { com } \\
\text { deficiência } \\
\text { visual }\end{array}$ & $\begin{array}{l}\text { Concluiu-se que a } \\
\text { ausência de } \\
\text { adaptações } \\
\text { curriculares nas } \\
\text { aulas de EF implica } \\
\text { em barreiras de } \\
\text { acesso e constitui } \\
\text { em impedimento } \\
\text { para o } \\
\text { aproveitamento da } \\
\text { aprendizagem por } \\
\text { parte dos } \\
\text { estudantes com } \\
\text { deficiência visual. }\end{array}$ & 2017 & $\begin{array}{l}\text { Camila de } \\
\text { Moura } \\
\text { Costa; Mey } \\
\text { de Abreu } \\
\text { van Munster }\end{array}$ & $\begin{array}{c}\text { Observação } \\
\text { sistemática e } \\
\text { entrevista } \\
\text { semiestruturada }\end{array}$ & $\begin{array}{l}3 \text { professores de } \\
\text { EF e } 4 \text { alunos com } \\
\text { deficiência visual }\end{array}$ \\
\hline
\end{tabular}




\section{usm

ISSN: 1984-6444 | http://dx.doi.org/10.5902/1984644442654

\section{Continuação Quadro 1 - Trabalhos Selecionados}

\begin{tabular}{|c|c|c|c|c|c|c|}
\hline TíTULO & OBJETIVO & $\begin{array}{l}\text { CONCLUSÃO } \\
\text { PRINCIPAL }\end{array}$ & ANO & AUTORES & INSTRUMENTO & PARTICIPANTES \\
\hline $\begin{array}{l}\text { Physical } \\
\text { Educatio } \\
\text { n classes } \\
\text { and } \\
\text { inclusion } \\
\text { of } \\
\text { children } \\
\text { with } \\
\text { disability: } \\
\text { Brazilian } \\
\text { Teachers' } \\
\text { Perspecti } \\
\text { ves }\end{array}$ & $\begin{array}{l}\text { Analisar o } \\
\text { conceito de } \\
\text { inclusão dos } \\
\text { professores de } \\
\text { EF e determinar } \\
\text { os aspectos } \\
\text { positivos e } \\
\text { negativos em } \\
\text { suas aulas }\end{array}$ & 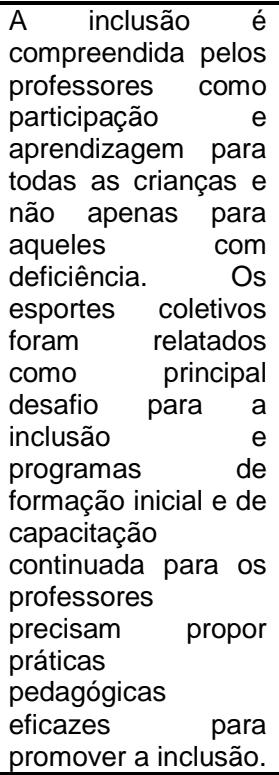 & 2017 & $\begin{array}{l}\text { Maria Luíza } \\
\text { Tanure } \\
\text { Alves et al. }\end{array}$ & $\begin{array}{c}\text { Entrevista } \\
\text { semiestruturada }\end{array}$ & $\begin{array}{c}18 \text { professores de } \\
\text { EF }\end{array}$ \\
\hline $\begin{array}{l}\text { Educação } \\
\text { Física } \\
\text { Escolar: } \\
\text { percepçõ } \\
\text { es do } \\
\text { aluno } \\
\text { com } \\
\text { deficiênci } \\
\text { a }\end{array}$ & $\begin{array}{c}\text { Compreender as } \\
\text { percepções do } \\
\text { aluno com } \\
\text { deficiência a } \\
\text { respeito das } \\
\text { aulas de EF }\end{array}$ & $\begin{array}{c}\text { Os alunos } \\
\text { apontaram que } \\
\text { gostar ou não das } \\
\text { aulas são aspectos } \\
\text { que podem ser } \\
\text { influenciados por } \\
\text { experiências de } \\
\text { exclusão que o } \\
\text { aluno com } \\
\text { deficiência vivencia, } \\
\text { assim como a falta } \\
\text { de adaptações nas } \\
\text { atividades. }\end{array}$ & 2016 & $\begin{array}{l}\text { Marcella } \\
\text { Fernandes } \\
\text { Paticcié } \\
\text { Nacif et al. }\end{array}$ & $\begin{array}{c}\text { Entrevista } \\
\text { semiestruturada }\end{array}$ & $\begin{array}{l}20 \text { alunos com } \\
\text { diferentes } \\
\text { deficiências }\end{array}$ \\
\hline $\begin{array}{c}\text { Educação } \\
\text { Física, } \\
\text { Deficiênci } \\
\text { a e } \\
\text { Inclusão } \\
\text { Escolar }\end{array}$ & $\begin{array}{c}\text { Compreender as } \\
\text { condições de } \\
\text { participação de } \\
\text { uma aluna com } \\
\text { deficiência } \\
\text { intelectual nas } \\
\text { aulas de } \\
\text { Educação Física }\end{array}$ & $\begin{array}{l}\text { Com o planejamento } \\
\text { e a atuação } \\
\text { intencional dos } \\
\text { educadores, é } \\
\text { possível realizar um } \\
\text { trabalho de inclusão } \\
\text { escolar, que vise o } \\
\text { acesso aos } \\
\text { conhecimentos } \\
\text { esperados na } \\
\text { disciplina de } \\
\text { Educação Física. }\end{array}$ & 2016 & $\begin{array}{l}\text { Rodrigo } \\
\text { Barbuio; } \\
\text { Ana Paula } \\
\text { de Freitas }\end{array}$ & $\begin{array}{l}\text { Observação e } \\
\text { Diário de Campo }\end{array}$ & $\begin{array}{c}1 \text { aluna com } \\
\text { deficiência } \\
\text { intelectual e } 1 \\
\text { professora de EF }\end{array}$ \\
\hline $\begin{array}{c}\text { O uso da } \\
\text { Tecnologi } \\
\text { a } \\
\text { Assistiva } \\
\text { por } \\
\text { professor } \\
\text { es de } \\
\text { Educação } \\
\text { Física }\end{array}$ & $\begin{array}{l}\text { Investigar as } \\
\text { formas de } \\
\text { atuação dos } \\
\text { professores de } \\
\text { EF envolvendo } \\
\text { alunos com } \\
\text { deficiência e os } \\
\text { meios de } \\
\text { adaptação de } \\
\text { suas aulas, } \\
\text { sondando a } \\
\text { respeito do uso } \\
\text { da TA }\end{array}$ & $\begin{array}{c}\text { Identificaram-se } \\
\text { adaptações e } \\
\text { improvisos nas } \\
\text { atividades } \\
\text { envolvendo alunos } \\
\text { com deficiência, } \\
\text { sendo que a TA não } \\
\text { é conhecida pela } \\
\text { maioria. }\end{array}$ & 2016 & $\begin{array}{l}\text { Natasha } \\
\text { Reis } \\
\text { Ferreira; } \\
\text { Leandro } \\
\text { Penna } \\
\text { Ranieri }\end{array}$ & $\begin{array}{c}\text { Entrevista } \\
\text { semiestruturada }\end{array}$ & $\begin{array}{c}6 \text { professores de } \\
\text { EF }\end{array}$ \\
\hline
\end{tabular}




\section{usm Alllbapat

ISSN: 1984-6444 | http://dx.doi.org/10.5902/1984644442654

\section{Continuação Quadro 1 - Trabalhos Selecionados}

\begin{tabular}{|c|c|c|c|c|c|c|}
\hline TíTULO & OBJETIVO & $\begin{array}{l}\text { CONCLUSÃO } \\
\text { PRINCIPAL }\end{array}$ & ANO & AUTORES & INSTRUMENTO & PARTICIPANTES \\
\hline $\begin{array}{c}\text { Possibilidades } \\
\text { de } \\
\text { aprendizagem } \\
\text { de um aluno } \\
\text { com cegueira } \\
\text { no contexto da } \\
\text { Educação } \\
\text { Física Escolar }\end{array}$ & $\begin{array}{c}\text { Buscar } \\
\text { indícios das } \\
\text { possibilidad } \\
\text { es de } \\
\text { aprender de } \\
\text { um aluno } \\
\text { com } \\
\text { cegueira, } \\
\text { durante as } \\
\text { aulas de EF }\end{array}$ & $\begin{array}{c}\text { As ações } \\
\text { pedagógicas } \\
\text { intencionais da } \\
\text { professora, } \\
\text { mediadas pelas } \\
\text { palavras e gestos e } \\
\text { em situações } \\
\text { interativas, } \\
\text { possibilitaram o } \\
\text { acesso do aluno } \\
\text { com deficiência } \\
\text { visual aos } \\
\text { conteúdos } \\
\text { trabalhados. }\end{array}$ & 2016 & $\begin{array}{l}\text { José Milton } \\
\text { Azevedo } \\
\text { Andrade; } \\
\text { Ana Paula } \\
\text { de Freitas }\end{array}$ & $\begin{array}{l}\text { Videogravação } \\
\text { das aulas }\end{array}$ & 1 aluno cego \\
\hline $\begin{array}{c}\text { Possibilidades } \\
\text { de atuação do } \\
\text { professor de } \\
\text { Educação } \\
\text { Física no } \\
\text { processo de } \\
\text { aprendizagem } \\
\text { de alunos com } \\
\text { deficiência }\end{array}$ & $\begin{array}{l}\text { Analisar os } \\
\text { modos de } \\
\text { agir do } \\
\text { professor de } \\
\text { Educação } \\
\text { Física na } \\
\text { inclusão de } \\
\text { alunos com } \\
\text { deficiência } \\
\text { na escola } \\
\text { regular }\end{array}$ & $\begin{array}{l}\text { Foi possível apontar } \\
\text { indícios de que a } \\
\text { função docente é } \\
\text { preponderante na } \\
\text { organização das } \\
\text { possibilidades de } \\
\text { participação, } \\
\text { aprendizagem e } \\
\text { desenvolvimento } \\
\text { dos alunos com } \\
\text { deficiência, desde } \\
\text { que sejam } \\
\text { oportunizadas } \\
\text { estratégias que } \\
\text { considerem as } \\
\text { singularidades } \\
\text { desses alunos. }\end{array}$ & 2016 & $\begin{array}{l}\text { José Milton } \\
\text { Azevedo } \\
\text { Andrade; } \\
\text { Ana Paula } \\
\text { De Freitas }\end{array}$ & $\begin{array}{l}\text { Videogravação } \\
\text { das aulas }\end{array}$ & $\begin{array}{c}2 \text { professoras de } \\
\text { EF }\end{array}$ \\
\hline $\begin{array}{c}\text { A percepção } \\
\text { dos alunos } \\
\text { com } \\
\text { deficiência } \\
\text { sobre a sua } \\
\text { inclusão nas } \\
\text { aulas de } \\
\text { Educação } \\
\text { Física escolar: } \\
\text { um estudo de } \\
\text { caso } \\
\end{array}$ & $\begin{array}{l}\text { Investigar a } \\
\text { inclusão } \\
\text { partir da } \\
\text { perspectiva } \\
\text { do aluno } \\
\text { com } \\
\text { deficiência } \\
\text { dentro do } \\
\text { contexto das } \\
\text { aulas de EF } \\
\text { escolar } \\
\end{array}$ & $\begin{array}{l}\text { A inclusão no } \\
\text { contexto das aulas } \\
\text { de EF esteve } \\
\text { vinculada a três } \\
\text { fatores: adaptação, } \\
\text { participação social e } \\
\text { capacidade. }\end{array}$ & 2014 & $\begin{array}{l}\text { Maria Luíza } \\
\text { Tanure } \\
\text { Alves; } \\
\text { Edison } \\
\text { Duarte }\end{array}$ & $\begin{array}{c}\text { Entrevista } \\
\text { semiestruturada } \\
\text { e anotações de } \\
\text { campo }\end{array}$ & $\begin{array}{c}3 \text { estudantes } \\
\text { (entre } 12 \text { e } 21 \\
\text { anos) com } \\
\text { deficiência visual } \\
\text { ou física }\end{array}$ \\
\hline $\begin{array}{l}\text { Educação } \\
\text { Física } \\
\text { Inclusiva: } \\
\text { Atitudes dos } \\
\text { Docentes }\end{array}$ & $\begin{array}{l}\text { Descrever } \\
\text { as atitudes } \\
\text { inclusivas de } \\
53 \text { docentes } \\
\text { de EF a } \\
\text { lecionar em } \\
\text { escolas } \\
\text { públicas do } \\
\text { Distrito do } \\
\text { Porto - } \\
\text { Portugal }\end{array}$ & $\begin{array}{c}\text { Concluiu-se a } \\
\text { necessidade de } \\
\text { investir na formação } \\
\text { específica dos } \\
\text { docentes, no apoio } \\
\text { multidisciplinar, na } \\
\text { diferenciação } \\
\text { curricular, nas } \\
\text { infraestruturas e na } \\
\text { participação ativa de } \\
\text { toda a comunidade } \\
\text { educativa. }\end{array}$ & 2014 & $\begin{array}{l}\text { Celina Luísa } \\
\text { Raimundo } \\
\text { Martins }\end{array}$ & $\begin{array}{c}\text { Questionário } \\
\text { desenvolvido } \\
\text { para avaliar a } \\
\text { Atitude Global } \\
\text { Inclusiva: "A EF } \\
\text { e a Inclusão de } \\
\text { alunos com } \\
\text { NEE" e a escala } \\
\text { de Likert. }\end{array}$ & $\begin{array}{l}53 \text { docentes de } \\
\text { EF do Distrito do } \\
\text { Porto - Portugal }\end{array}$ \\
\hline
\end{tabular}




\section{usm Alltbapâ

ISSN: 1984-6444 | http://dx.doi.org/10.5902/1984644442654

\section{Continuação Quadro 1 - Trabalhos Selecionados}

\begin{tabular}{|c|c|c|c|c|c|c|}
\hline TíTULO & OBJETIVO & $\begin{array}{l}\text { CONCLUSÃO } \\
\text { PRINCIPAL }\end{array}$ & ANO & AUTORES & INSTRUMENTO & PARTICIPANTES \\
\hline $\begin{array}{l}\text { Inclusão de } \\
\text { alunos com } \\
\text { deficiência } \\
\text { na aula de } \\
\text { Educação } \\
\text { Física: } \\
\text { identificando } \\
\text { dificuldades, } \\
\text { ações e } \\
\text { conteúdos } \\
\text { para prover a } \\
\text { formação do } \\
\text { professor }\end{array}$ & $\begin{array}{c}\text { Identificar as } \\
\text { dificuldades } \\
\text { encontradas } \\
\text { por } \\
\text { professores } \\
\text { de EF para } \\
\text { incluir } \\
\text { alunos com } \\
\text { deficiência e } \\
\text { sugerir } \\
\text { ações e } \\
\text { conteúdos a } \\
\text { partir dessas } \\
\text { dificuldades } \\
\text { com a } \\
\text { intenção de } \\
\text { promover a } \\
\text { formação } \\
\text { dos } \\
\text { professores }\end{array}$ & $\begin{array}{c}\text { Ao propor uma } \\
\text { formação para } \\
\text { professores de EF, } \\
\text { com foco na inclusão } \\
\text { educacional, é preciso } \\
\text { identificar e assumir } \\
\text { as dificuldades } \\
\text { encontradas, uma vez } \\
\text { que os professores } \\
\text { relataram que a } \\
\text { dificuldade não era, } \\
\text { somente, saber o que } \\
\text { fazer para incluir, ou } \\
\text { qual recurso } \\
\text { selecionar, mas que } \\
\text { havia outras questões, } \\
\text { como, as } \\
\text { administrativas, as } \\
\text { familiares e as } \\
\text { decorrentes da } \\
\text { estrutura escolar. }\end{array}$ & 2014 & $\begin{array}{l}\text { Maria Luiza } \\
\text { Salzani } \\
\text { Fiorini; } \\
\text { Eduardo } \\
\text { José } \\
\text { Manzini }\end{array}$ & $\begin{array}{l}\text { Grupo focal; } \\
\text { roteiro com } \\
\text { questões } \\
\text { abertas }\end{array}$ & $\begin{array}{c}17 \text { professores de } \\
\text { EF }\end{array}$ \\
\hline $\begin{array}{c}\text { Representaç } \\
\text { ões de } \\
\text { alunos } \\
\text { surdos sobre } \\
\text { a inclusão } \\
\text { nas aulas de } \\
\text { Educação } \\
\text { Física }\end{array}$ & $\begin{array}{l}\text { Analisar as } \\
\text { representaç } \\
\text { ões de } \\
\text { alunos } \\
\text { surdos } \\
\text { sobre sua } \\
\text { inclusão nas } \\
\text { aulas de } \\
\text { Educação } \\
\text { Física }\end{array}$ & $\begin{array}{c}\text { A inclusão dos surdos } \\
\text { nas aulas de EF ainda } \\
\text { não se efetivou, } \\
\text { mesmo tendo } \\
\text { encontrado alguns } \\
\text { professores com } \\
\text { ações pedagógicas } \\
\text { que demonstraram } \\
\text { serem inclusivas, } \\
\text { contudo, elas ainda } \\
\text { deixam várias lacunas } \\
\text { no que diz respeito a } \\
\text { uma aprendizagem } \\
\text { satisfatória dos } \\
\text { alunos. }\end{array}$ & 2014 & $\begin{array}{c}\text { Tássia } \\
\text { Pereira } \\
\text { Alves et al. }\end{array}$ & $\begin{array}{c}\text { Entrevista } \\
\text { semiestruturada }\end{array}$ & 8 alunos surdos \\
\hline $\begin{array}{c}\text { A exclusão } \\
\text { nas aulas de } \\
\text { Educação } \\
\text { Física: } \\
\text { fatores } \\
\text { associados } \\
\text { com } \\
\text { participação } \\
\text { de alunos } \\
\text { com } \\
\text { deficiência }\end{array}$ & $\begin{array}{c}\text { Analisar os } \\
\text { fatores } \\
\text { relacionados } \\
\text { com a } \\
\text { exclusão do } \\
\text { aluno com } \\
\text { deficiência } \\
\text { nas aulas de } \\
\text { EF }\end{array}$ & $\begin{array}{c}\text { A exclusão está } \\
\text { associada com a falta } \\
\text { de adaptação nas } \\
\text { aulas, isolamento } \\
\text { social e sentimento de } \\
\text { inferioridade. }\end{array}$ & 2013 & $\begin{array}{c}\text { Maria Luíza } \\
\text { Tanure } \\
\text { Alves; } \\
\text { Edison } \\
\text { Duarte }\end{array}$ & $\begin{array}{c}\text { Entrevista } \\
\text { semiestruturada } \\
\text { e anotações de } \\
\text { campo }\end{array}$ & $\begin{array}{c}3 \text { estudantes com } \\
\text { deficiência visual } \\
\text { ou física }\end{array}$ \\
\hline $\begin{array}{c}\text { A preparação } \\
\text { do } \\
\text { profissional } \\
\text { de Educação } \\
\text { Física para a } \\
\text { inclusão de } \\
\text { alunos com } \\
\text { deficiência }\end{array}$ & $\begin{array}{c}\text { Avaliar a } \\
\text { preparação } \\
\text { dos } \\
\text { professores } \\
\text { de EF, de } \\
\text { escolas } \\
\text { públicas e } \\
\text { particulares, } \\
\text { de duas } \\
\text { cidades do } \\
\text { sul de Minas } \\
\text { Gerais }\end{array}$ & $\begin{array}{l}\text { Os professores } \\
\text { recebem esses alunos } \\
\text { em suas aulas, porém } \\
\text { não se sentem } \\
\text { preparados e por isso } \\
\text { muitas vezes não } \\
\text { realizam a "verdadeira } \\
\text { inclusão", deixando } \\
\text { apenas que o aluno } \\
\text { esteja presente em } \\
\text { sua aula. }\end{array}$ & 2013 & $\begin{array}{l}\text { Michelle } \\
\text { Aline } \\
\text { Barreto et al. }\end{array}$ & $\begin{array}{c}\text { Entrevista } \\
\text { semiestruturada }\end{array}$ & $\begin{array}{c}20 \text { professores de } \\
\text { EF }\end{array}$ \\
\hline
\end{tabular}




\section{usm

ISSN: 1984-6444 | http://dx.doi.org/10.5902/1984644442654

\section{Continuação Quadro 1 - Trabalhos Selecionados}

\begin{tabular}{|c|c|c|c|c|c|c|}
\hline TÍTULO & OBJETIVO & $\begin{array}{l}\text { CONCLUSÃO } \\
\text { PRINCIPAL }\end{array}$ & ANO & AUTORES & INSTRUMENTO & PARTICIPANTES \\
\hline $\begin{array}{l}\text { Inclusão de } \\
\text { alunos com } \\
\text { surdez na } \\
\text { Educação } \\
\text { Física } \\
\text { Escolar }\end{array}$ & $\begin{array}{l}\text { Apreender as } \\
\text { representações } \\
\text { de alunos com } \\
\text { surdez sobre } \\
\text { sua inclusão nas } \\
\text { aulas de EF } \\
\text { Escolar }\end{array}$ & $\begin{array}{l}\text { Os professores eram } \\
\text { preocupados com o } \\
\text { aprendizado dos } \\
\text { alunos surdos em } \\
\text { contrapartida, } \\
\text { identificou-se que a } \\
\text { prática pedagógica de } \\
\text { outros docentes não } \\
\text { considerava as } \\
\text { necessidades } \\
\text { educacionais de seus } \\
\text { alunos com surdez }\end{array}$ & 2013 & $\begin{array}{c}\text { Tássia } \\
\text { Pereira } \\
\text { Alves et al. }\end{array}$ & $\begin{array}{c}\text { Entrevista } \\
\text { semiestruturada }\end{array}$ & $\begin{array}{l}8 \text { alunos com } \\
\text { surdez }\end{array}$ \\
\hline $\begin{array}{c}\text { Aulas de } \\
\text { Educação } \\
\text { Física e } \\
\text { Inclusão: um } \\
\text { estudo de } \\
\text { caso com a } \\
\text { deficiência } \\
\text { física }\end{array}$ & $\begin{array}{l}\text { Descrever a } \\
\text { participação de } \\
\text { um aluno com } \\
\text { deficiência física } \\
\text { em aulas de EF } \\
\text { em uma turma } \\
\text { do } 2^{\circ} \text { ano do } \\
\text { Ensino } \\
\text { Fundamental de } \\
\text { uma escola } \\
\text { regular }\end{array}$ & $\begin{array}{c}\text { A inclusão está } \\
\text { ocorrendo de forma } \\
\text { parcial na turma em } \\
\text { questão, } \\
\text { especialmente nas } \\
\text { aulas de EF, levando- } \\
\text { se em consideração } \\
\text { que o aluno com } \\
\text { deficiência física não } \\
\text { participou de todas as } \\
\text { atividades } \\
\text { desenvolvidas }\end{array}$ & 2012 & $\begin{array}{c}\text { Luciana } \\
\text { Erina Palma; } \\
\text { Greice } \\
\text { Rosso } \\
\text { Lehnhard }\end{array}$ & $\begin{array}{c}\text { Observação e } \\
\text { entrevista } \\
\text { semiestruturada }\end{array}$ & $\begin{array}{c}\text { Aluno com } \\
\text { paralisia cerebral }\end{array}$ \\
\hline $\begin{array}{c}\text { A } \\
\text { participação } \\
\text { de alunos } \\
\text { com } \\
\text { Síndrome de } \\
\text { Down nas } \\
\text { aulas de } \\
\text { Educação } \\
\text { Física } \\
\text { escolar: um } \\
\text { estudo de } \\
\text { caso }\end{array}$ & $\begin{array}{l}\text { Observar a } \\
\text { realidade da } \\
\text { inclusão da } \\
\text { criança com } \\
\text { síndrome de } \\
\text { Down (SD) nas } \\
\text { aulas de EF } \\
\text { escolar, } \\
\text { identificando os } \\
\text { obstáculos e } \\
\text { facilidades } \\
\text { encontrados por } \\
\text { ela. }\end{array}$ & $\begin{array}{c}\text { O aluno com SD } \\
\text { apresentou } \\
\text { dificuldades para } \\
\text { participar socialmente } \\
\text { junto à turma, embora } \\
\text { não apresentasse } \\
\text { dificuldades para } \\
\text { compreensão e } \\
\text { execução das } \\
\text { atividades propostas } \\
\text { em aula. }\end{array}$ & 2012 & $\begin{array}{c}\text { Maria Luíza } \\
\text { Tanure } \\
\text { Alves; } \\
\text { Edison } \\
\text { Duarte }\end{array}$ & $\begin{array}{l}\text { Observação } \\
\text { sistemática }\end{array}$ & $\begin{array}{c}1 \text { aluno com } \\
\text { Síndrome de } \\
\text { Down }\end{array}$ \\
\hline $\begin{array}{c}\text { Capacitação } \\
\text { de } \\
\text { professores } \\
\text { para inclusão } \\
\text { de pessoas } \\
\text { deficientes } \\
\text { nas aulas de } \\
\text { educação } \\
\text { física }\end{array}$ & $\begin{array}{l}\text { Avaliar em que } \\
\text { medida a } \\
\text { SEEDF vem } \\
\text { atendendo as } \\
\text { necessidades de } \\
\text { capacitação e } \\
\text { acompanhament } \\
\text { o pedagógico } \\
\text { dos professores } \\
\text { de Educação } \\
\text { Física para } \\
\text { efetivação do } \\
\text { processo de } \\
\text { inclusão de } \\
\text { alunos com } \\
\text { deficiência em } \\
\text { suas aulas, além } \\
\text { de verificar se } \\
\text { os professores } \\
\text { se sentem } \\
\text { capacitados } \\
\text { para efetivar a } \\
\text { inclusão desses } \\
\text { alunos nas aulas }\end{array}$ & $\begin{array}{c}\text { Partes dos } \\
\text { professores não se } \\
\text { sentem capacitados } \\
\text { para efetivar o } \\
\text { processo de inclusão } \\
\text { e que leva à } \\
\text { necessidade do } \\
\text { desencadeamento de } \\
\text { um processo, por } \\
\text { parte da SEEDF, de } \\
\text { discussão a respeito } \\
\text { da inclusão, seguindo } \\
\text { as determinações da } \\
\text { Resolução 2/2001 do } \\
\text { CNE/CEB. }\end{array}$ & 2012 & $\begin{array}{c}\text { Elvio M. } \\
\text { Boato; Tânia } \\
\text { M. V. } \\
\text { Sampaio; } \\
\text { Junior V. P. } \\
\text { da Silva. }\end{array}$ & Questionário & $\begin{array}{l}180 \\
\text { Professores de EF }\end{array}$ \\
\hline
\end{tabular}




\section{Tusm \\ ISSN: 1984-6444

ISSN: 1984-6444 | http://dx.doi.org/10.5902/1984644442654

Continuação Quadro 1 - Trabalhos Selecionados

\begin{tabular}{|c|c|c|c|c|c|c|}
\hline TíTULO & OBJETIVO & $\begin{array}{c}\text { CONCLUSÃO } \\
\text { PRINCIPAL }\end{array}$ & ANO & AUTORES & INSTRUMENTO & PARTICIPANTES \\
\hline $\begin{array}{c}\text { Os } \\
\text { deficientes } \\
\text { auditivos nas } \\
\text { aulas de } \\
\text { Educação } \\
\text { Física: } \\
\text { repensando } \\
\text { as } \\
\text { possibilidade } \\
\text { s de } \\
\text { atividades } \\
\text { pedagógicas } \\
\text { inclusivas }\end{array}$ & $\begin{array}{l}\text { Analisou quais } \\
\text { são as } \\
\text { atividades } \\
\text { pedagógicas } \\
\text { utilizadas pelos } \\
\text { professores de } \\
\text { EF para incluir } \\
\text { os alunos com } \\
\text { deficiência } \\
\text { auditiva }\end{array}$ & $\begin{array}{l}\text { A inclusão de alunos } \\
\text { deficientes auditivos } \\
\text { nas aulas de EF é } \\
\text { possível, sendo } \\
\text { necessárias algumas } \\
\text { mudanças na forma } \\
\text { de realizar as } \\
\text { atividades. }\end{array}$ & 2012 & $\begin{array}{c}\text { Flávia } \\
\text { Temponi } \\
\text { Góes; Ana } \\
\text { Caroline } \\
\text { Alves; Paulo } \\
\text { Roberto } \\
\text { Vieira Júnior }\end{array}$ & $\begin{array}{c}\text { Entrevista } \\
\text { semiestruturada }\end{array}$ & $\begin{array}{c}4 \text { professores de } \\
\text { EF }\end{array}$ \\
\hline $\begin{array}{l}\text { Educação } \\
\text { Física e } \\
\text { Inclusão: a } \\
\text { experiência } \\
\text { na Escola } \\
\text { Azul }\end{array}$ & $\begin{array}{l}\text { Investigar e } \\
\text { analisar o } \\
\text { processo de } \\
\text { inclusão de dois } \\
\text { alunos com } \\
\text { (NEEs) no } \\
\text { espaço-tempo } \\
\text { das aulas de EF }\end{array}$ & $\begin{array}{c}\text { Na Escola Azul, a } \\
\text { inclusão se revelou } \\
\text { ora possível e } \\
\text { palpável, ora utópica e } \\
\text { distante, com } \\
\text { possibilidades, mas } \\
\text { também com limites. }\end{array}$ & 2011 & $\begin{array}{l}\text { José } \\
\text { Chicon; } \\
\text { Katiuscia } \\
\text { Mendes; } \\
\text { Marias das } \\
\text { Graças Sá }\end{array}$ & $\begin{array}{c}\text { Diário de campo } \\
\text { e a observação } \\
\text { participante }\end{array}$ & $\begin{array}{c}2 \text { alunos, um com } \\
\text { baixa visão, e o } \\
\text { outro com } \\
\text { Síndrome de } \\
\text { Down }\end{array}$ \\
\hline $\begin{array}{c}\text { Inclusão } \\
\text { escolar na } \\
\text { Educação } \\
\text { Física: } \\
\text { reflexões } \\
\text { acerca da } \\
\text { formação } \\
\text { docente } \\
\text { educacional }\end{array}$ & $\begin{array}{l}\text { Compreender } \\
\text { como vem se } \\
\text { dando o } \\
\text { processo de } \\
\text { inclusão na EF } \\
\text { escolar dos } \\
\text { estudantes } \\
\text { deficientes } \\
\text { visuais incluídos } \\
\text { (as) na } \\
\text { Educação } \\
\text { Básica }\end{array}$ & $\begin{array}{c}\text { Os resultados nos } \\
\text { mostraram que o } \\
\text { processo de inclusão } \\
\text { em relação à EF } \\
\text { escolar encontra } \\
\text { dificuldades para se } \\
\text { efetivar, dada à má } \\
\text { preparação e } \\
\text { formação docente. }\end{array}$ & 2010 & $\begin{array}{c}\text { Vanderlei } \\
\text { Balbino da } \\
\text { Costa }\end{array}$ & $\begin{array}{c}\text { Observação e } \\
\text { entrevista }\end{array}$ & $\begin{array}{c}6 \text { alunos com } \\
\text { deficiência visual }\end{array}$ \\
\hline
\end{tabular}

Fonte: Os autores (2020).

\section{Discussão dos Resultados}

A partir da Análise de Conteúdo aplicada aos 22 artigos selecionados, identificamos alguns elementos em comum que se destacavam nos trabalhos e que, conforme os autores, são fatores que podem potencializar e/ou dificultar a inclusão de alunos com deficiência nas aulas de Educação Física. Desta forma, os conteúdos dos trabalhos foram desmembrados em unidades e reagrupados analogicamente. Estabelecendo-se a partir disso as seguintes categorias elencadas para a discussão: Estratégias de Ensino, Trabalho Colaborativo e Formação. 


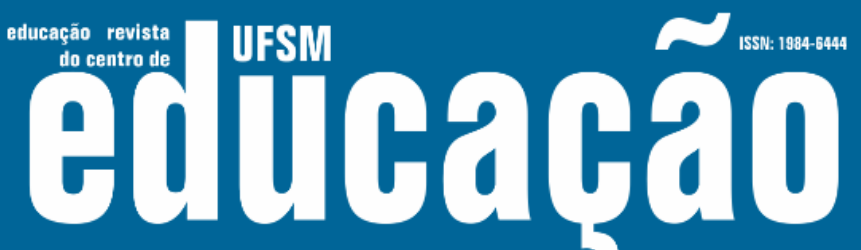

ISSN: 1984-6444 | http://dx.doi.org/10.5902/1984644442654

poderiam se limitar as disciplinas específicas, mas que a temática em questão constituísse toda a grade curricular.

$\mathrm{Na}$ literatura investigada, alguns pontos de dificuldades na formação inicial são elencados: professores formados antes dos anos de 1990 apresentaram uma visão mais limitada sobre inclusão; ausência de uma disciplina que abrangesse o tema inclusão; disciplina destinada somente a uma deficiência em específico; ausência de experiências em estágios e pouco conhecimento teórico (ALVES et al., 2017; FERREIRA; RANIERI, 2016; FIORINI; MANZINI, 2014).

Ao comparar professores com e sem formação continuada, Martins (2014) percebeu que o grupo sem formação apresentou insegurança sobre a eficácia de suas aulas. A ausência dessa formação surge, ainda, como um dos fatores preponderantes em atitudes menos inclusivas dos professores. Nesta perspectiva, a formação continuada foi vista com bons olhos por Greguol (2018), que encontrou atitudes mais positivas em professores que buscaram cursos de extensão e lato sensu referentes ao tema inclusão.

Alguns estudos também identificaram lacunas presentes nas formações continuadas dos professores, seja em cursos de curta duração ou em cursos de pósgraduação. Os trabalhos apontam que os cursos não abordam as realidades encontradas nas escolas; muitas vezes são específicos para atender uma deficiência; e ainda ausência de cursos ofertados pelas instituições ou secretarias de educação (BARRETO et al., 2013; BOATO, SAMPAIO, SILVA, 2012; FIORINI, MANZINI, 2014, 2018; MARTINS, 2014).

Ao observarmos as diversas lacunas existentes na formação inicial e continuada, percebemos alguns caminhos que poderão ser seguidos para que estas barreiras sejam minimizadas, como uma formação inicial que busque envolver mais o discente nas práticas escolares. Já Fiorini e Manzini (2014) apontam que a formação continuada poderia partir das necessidades que os professores relatam, para que então houvesse o planejamento junto com a secretaria e instituições sobre a maneira que os cursos irão ocorrer, além de mais incentivos aos docentes. Nesta perspectiva, Boato, Sampaio e Silva (2012) consideram essencial que as secretarias de educação ofereçam aos profissionais: cursos, palestras e reuniões para que se discuta a 


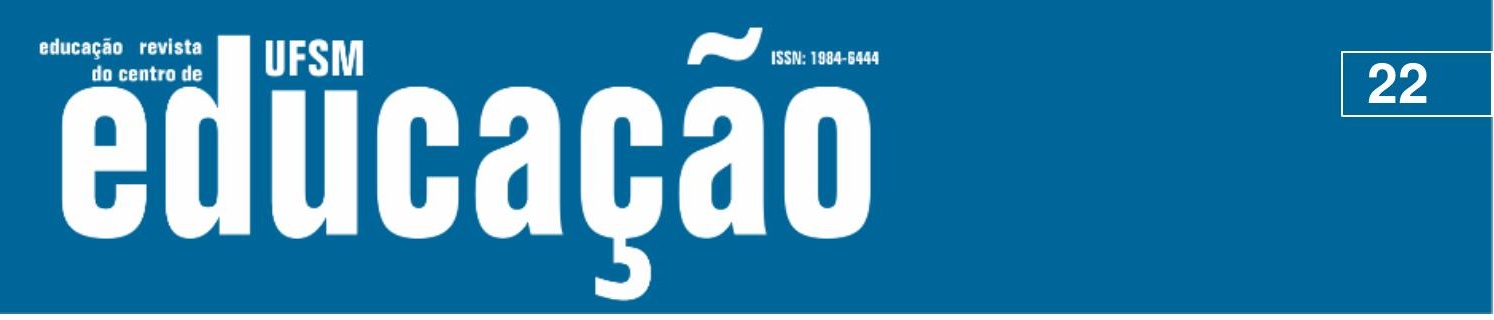

ISSN: 1984-6444 | http://dx.doi.org/10.5902/1984644442654

executar distintas situações que busquem a participação de todos os alunos nas aulas de Educação Física.

Nesta concepção, com base nos resultados encontrados, cremos que a educação é um dos campos do conhecimento e ação humana mais promissora para a tomada de consciência da crise em que vivemos, gerando transformações e novos significados. Por isso, compreende-se a necessidade e urgência de investir em processos de mudanças na formação do profissional de Educação Física, pois é sobre eles que recaem as exigências da sociedade quanto à formação de suas crianças e adolescentes no tocante a torná-los cidadãos que devem agir de forma crítica e participativa.

\section{Agradecimentos}

O presente trabalho foi realizado com apoio da Fundação de Amparo à Pesquisa do Estado do Amazonas - FAPEAM.

\section{Referências}

ALMEIDA, Monaliza Soares Azevedo de; NETO, Valmir Arruda de Sousa; MELO, Eduardo de Lima. Alunos com Deficiência na Escola Pública: Inclusão de Deficientes Físicos nas Aulas de Educação Física. REDFOCO, v. 3, n. 1, p. 55-67. 2016.

ALVES, Maria Luíza Tanure et al. Physical Education Classes and Inclusion of Children with Disability: Brazilian Teachers' Perspectives. Movimento (ESEFID/UFRGS), v. 23, n. 4, p. 1229-1244, out./dez. 2017.

ALVES, Maria Luíza Tanure M. L. T.; DUARTE, E. A participação de alunos com síndrome de down nas aulas de educação física escolar: Um estudo de caso. Movimento (ESEFID/UFRGS), v. 18, n. 3, p. 237-256, jul./set. 2012.

ALVES, Maria Luíza Tanure; DUARTE, Edison. A exclusão nas aulas de Educação Física: fatores associados com participação de alunos com deficiência. Movimento (ESEFID/UFRGS), v. 19, n. 1, p. 117-137, jan./mar. 2013.

ALVES, Maria Luíza Tanure; DUARTE, Edison. A percepção dos alunos com deficiência sobre a sua inclusão nas aulas de Educação Física escolar: um estudo de caso. Revista Brasileira de Educação Física e Esporte, v. 28, n. 2, p. 329-338, abr./jun. 2014. 


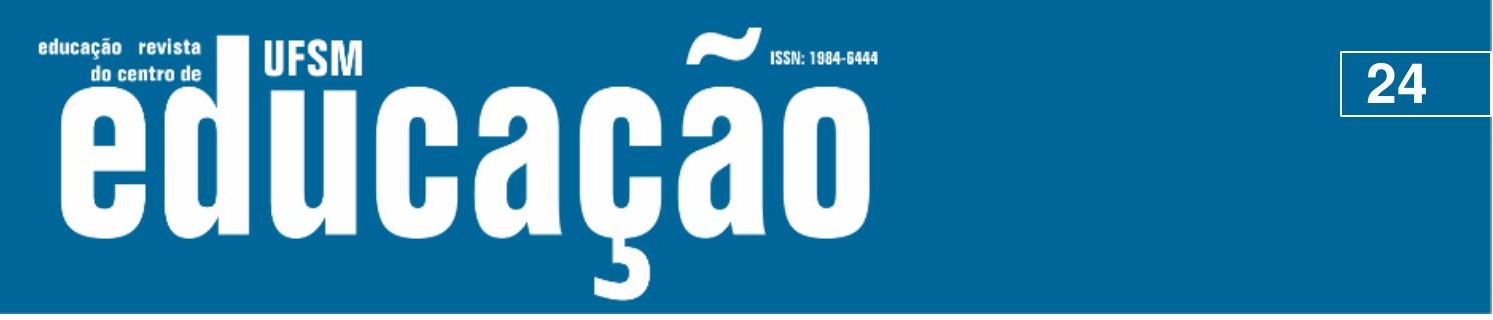

ISSN: 1984-6444 | http://dx.doi.org/10.5902/1984644442654

COSTA, Camila de Moura; MUNSTER, Mey de Abreu. Adaptações Curriculares nas Aulas de Educação Física Envolvendo Estudantes com Deficiência Visual. Rev. Bras. Ed. Esp, v. 23, n. 3, p. 361-376, jul./set. 2017.

COSTA, Vanderlei Balbino da. Inclusão escolar na educação física: reflexões acerca da formação docente. Motriz, v. 16, n. 4, p. 889-899, out./dez. 2010.

DAMIANI, Magda Floriana. Entendendo o trabalho colaborativo em educação e revelando seus benefícios. Educar. n.31, p. 213-230. 2008.

FERREIRA, Natasha Reis; RANIERI, Leandro Penna. O uso da tecnologia assistiva por professores de educação física. Revista Eletrônica de Educação, v. 10, n. 3, p. 215-229, març./jun.2016.

FIORINI, Maria Luiza Salzani; MANZINI, Eduardo José. Inclusão de alunos com deficiência na aula de educação física: identificando dificuldades, ações e conteúdos para prover a formação do professor. Revista Brasileira de Educação Especial, v. 20, n. 3, p. 387-404, jul./set. 2014.

FIORINI, Maria Luiza Salzani; MANZINI, Eduardo José. Dificuldades e Sucessos de Professores de Educação Física em relação à inclusão escolar. Rev. Bras. Ed. Esp, v. 22, n. 1, p. 49-64, jan./març. 2016.

FIORINI, Maria Luiza Salzani; MANZINI, Eduardo José. Estratégias de Professores de Educação Física para Promover a Participação de Alunos com Deficiência Auditiva nas Aulas. Rev. Bras. Ed. Esp, v. 24, n. 2, p. 183-198, abr./jun. 2018.

GALVÃO, Taís Freire; PANSANI, Thais de Souza Andrade; HARRAD, David. Principais itens para relatar Revisões sistemáticas e Meta-análises: A recomendação PRISMA. Epidemiol. Serv. Saúde, v. 24, n. 2, p. 335-342, abr./jun 2015.

GÓES, Flávia Temponi; ALVES, Ana Caroline; JÚNIOR, Paulo Roberto Vieira. Os deficientes auditivos nas aulas de educação física: repensando as possibilidades de atividades pedagógicas inclusivas. Revista Formação@Docente, v. 4, n. 1, p. 1-16, jun. 2012.

GREGUOL, Marcia; MALAGODI, Bruno Marson; CARRARO, Attilio. Inclusão de Alunos com deficiência nas Aulas de Educação Física: Atitudes de Professores nas escolas regulares. Revista Brasileira de Educação Especial, Marília, v. 24, n. 1, p. 33-44. 2018.

INEP. Sinopse Estatística da Educação Básica 2018. Brasilia: Inep, 2019. Disponivel em: http://portal.inep.gov.br/sinopses-estatisticas-da-educacao-basica. Acesso em: 20/01/2020. Laboratório de Pesquisa em Engenharia de Software. Disponível em: http://lapes.dc.ufscar.br/tools/start_tool. Acesso em 15. dez. 2019.

MANTOAN, Maria Teresa Égler. Inclusão escolar: O que é? Como fazer? 1 ed. São Paulo: Moderna, 2003. 


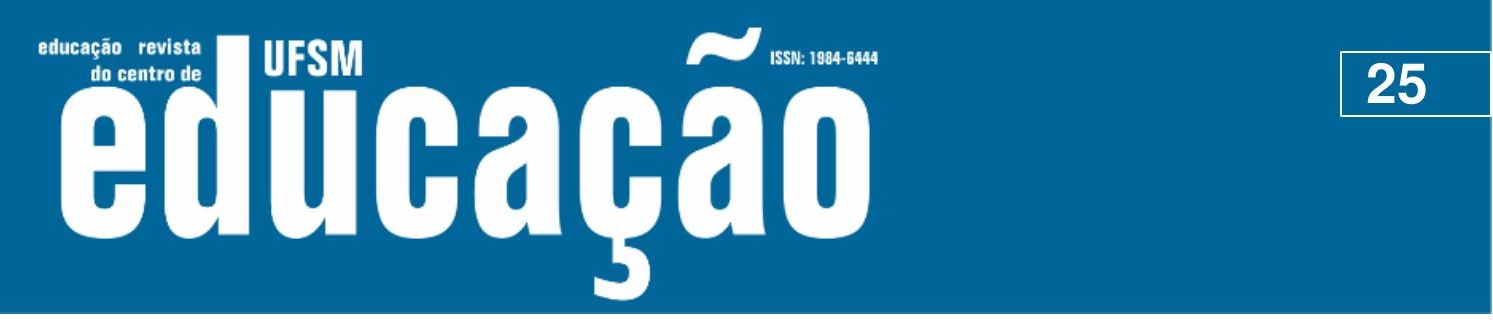

ISSN: 1984-6444 | http://dx.doi.org/10.5902/1984644442654

MARTINS, Celina Luísa Raimundo. Educação Física Inclusiva: Atitudes dos Docentes. Movimento Revista de Educação Físicada UFRGS, Porto Alegre, v. 20, n. 2, p. 637657. 2014.

MELETTI, Silvia Márcia Ferreira; BUENO, José Geraldo Silveira. A escolarização de alunos com deficiência: uma análise dos indicadores sociais no Brasil (1997-2006). In: Reunião Anual da ANPED, 33.; 2010, Caxambú. Educação no Brasil: o balanço de uma década, 2010. p.1-17.

NACIF, Marcella Fernandes Paticcié et al. Educação Física Escolar: Percepções do Aluno com Deficiência. Revista Brasileira de Educação Especial, v. 22, n. 1, p. 111124, jan./mar. 2016.

ONU. Declaração dos Direitos da Criança - 1959. Assembleia das Nações Unidas de 20 de novembro de 1959. ONU, v. 1386, n. XIV, p. 2-4, 1959.

PALMA, Luciana Erina; LEHNHARD, Greice Rosso. Aulas de educação física e inclusão: um estudo de caso com a deficiência física. Rev. Bras. Ed. Esp., v. 25, n. 42, p. 115-126, jan./ abr. 2012.

RODRIGUES, David. A Educação Física Perante a Educação Inclusiva: Reflexões Conceptuais e Metodológicas. Revista da Educação Física/UEM, v. 14, n. 1, p. 6773. jul./set. 2003.

SOUZA, Gisele Cristina de; $\mathrm{PICH}$, Santiago. A reorientação da ação pedagógica na Educação Física sob a perspectiva da inclusão: a pesquisa-ação como caminho. Movimento Revista de Educação Física da UFRGS, Porto Alegre, v. 19, n. 3, p. 149-169. 2013.

UNESCO. Declaração Mundial sobre Educação para Todos: satisfação das necessidades básicas de aprendizagem, Jomtien, 1990. 1998.

UNESCO. Declaração de Salamanca Sobre Princípios, Políticas e Práticas na Área das Necessidades Educativas Especiais, Espanha, 10 de junho de 1994.

\section{Correspondência}

Francianne Farias dos Santos - Universidade Federal do Amazonas - Avenida Rodrigo Otávio, Japiim, CEP 69077000, Manaus, Amazonas, Brasil.

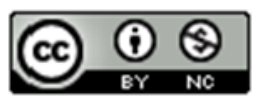

This work is licensed under a Creative Commons Attribution-NonCommercial 4.0 International (CC BY-NC 4.0) 